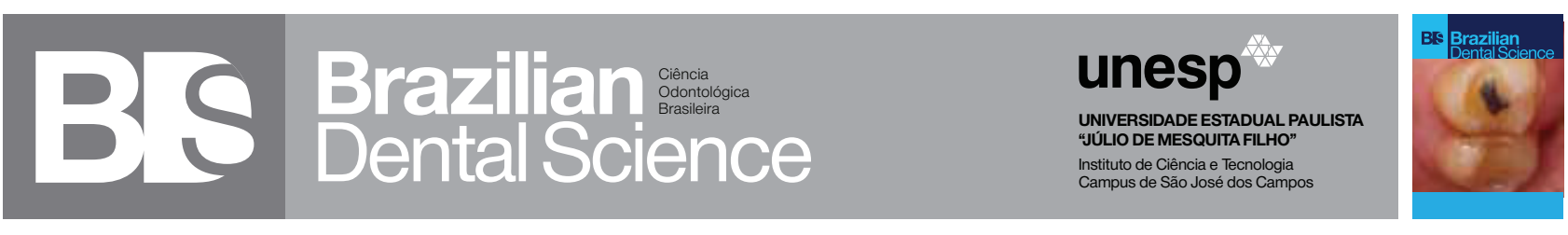

\title{
Schwartz-Jampel Syndrome: a paediatric dentistry approach
}

Síndrome de Schwartz-Jampel: uma abordagem odontopediátrica

Ana Paula Silveira TURRIONI ${ }^{1}$, Sarah Ayumi SAKIMA ${ }^{1}$, Elisa Maria Aparecida GIRO ${ }^{1}$

1 - School of Dentistry, UNESP - Univ Estadual Paulista, Department of Orthodontics and Paediatric Dentistry, Araraquara, SP , Brazil

\begin{abstract}
Schwartz-Jampel syndrome (SJS) is a rare recessive disorder characterized mainly by myotonia. As the clinical signs and symptoms are manifested in the oromaxillofacial region, paediatric dentists may be first choice of parents that seek information and assistance to their children. A female patient diagnosed with SJS was brought to our clinic for dental treatment with main complain of difficulty on oral hygiene and mastication due to tooth crowding. The treatment included preventive measures, extraction of a supernumerary tooth and the maxillary primary second molars. Furthermore, the patient was referred to orthodontic treatment for correction of tooth crowding. When dealing with children with confirmed diagnosis of SSJ, paediatric dentists should be understand the need of planning the dental treatment considering the characteristics and possible complications associated with the syndrome in order to reduce the risks to patients, especially when surgical procedures are necessary.
\end{abstract}

\section{KEYWORDS}

Supernumerary tooth; Malocclusion; Myotonia; Osteochondrodysplasias.

\section{BRIEF LITERATURE REVIEW}

Schwartz-Jampel syndrome (SJS) [MIM 255800] is a rare, congenital autosomal recessive disorder characterized by myotonia, muscular stiffness, multiple skeletal deformities (bone dysplasia), growth retardation and short stature $[1,2]$. The typical clinical signs and symptoms of SJS are

\section{RESUMO}

A síndrome de Schwartz Jampel (SSJ) é uma desordem autossômica recessiva rara, caracterizada principalmente pela miotonia. Desde que alguns dos sinais clínicos e sintomas são manifestados na região oromaxilofacial, o odontopediatra pode ser o primeiro profissional a se deparar com um paciente portador desta síndrome. Um paciente do sexo feminino diagnosticado com SJS procurou a nossa clínica para tratamento dental com queixa principal de dificuldade na realização da higiene oral e mastigação, devido ao mau posicionamento dentário. $\mathrm{O}$ tratamento incluiu medidas preventivas, extração de um dente supranumerário e dos segundos molares decíduos e encaminhamento para tratamento ortodôntico. Quando uma criança possui o diagnóstico confirmado para SSJ, o odontopediatra deve ter conhecimento específico para planejar e realizar o tratamento odontológico de forma adequada, considerando as características da síndrome e as possíveis complicações associadas, a fim de reduzir os riscos ao paciente, especialmente quando procedimentos cirúrgicos são necessários.

\section{PALAVRAS-CHAVE}

Dente supranumerário; Má oclusão; Miotonia; Síndrome de Schwartz-Jampel.

seen in the maxillofacial region and include narrow palpebral fissures (blepharophimosis), blepharospasms, hypertelorism, low-set ears, micrognathia, retrognathia, narrow, higharched palate, diffuse hypertrophy of the facial and masticatory muscles, myopia, pursed lips and microstomia, producing a distinctive masklike facies [3]. 
The skeletal malformations affect the jawbones, causing micrognathia and palate constriction, which lead to impaction, displacement and/or crowding of teeth and malocclusion [1]. The primary features of SJS manifest within the first years of life, ranging in severity from mild myotonia with a few bone anomalies, which can only be detected radiographically to more severe problems which may lead to death [3-6].

Depending on the phenotypical characteristics, SJS can be categorized into type 1, which is subdivided according to the age of appearance of the signs and degree of bone dysplasia, and type 2 . Type $1 \mathrm{~A}$ is recognized in childhood and displays moderate bone dysplasia, while type $1 \mathrm{~B}$ is apparent at birth and has more prominent bone dysplasia. Type 2 is the severe neonatal form of the disease, with high infantile mortality rate, typical myotonia and contractures, and greater tendency to malignant hyperthermia [6].

Malformative syndromes require an early and accurate diagnosis without which it is impossible to establish a correct treatment plan. As the clinical signs and symptoms of SJS are manifested in the oromaxillofacial region, paediatric dentists may be faced with children with SJS in their daily practice and should be familiar with the clinical manifestations and possible implications of this syndrome in order to provide the best dental care possible.

This paper summarizes the clinical presentation of SJS and discusses on relevant points to be considered by paediatric dentists dealing with patients with this condition in order to plan the most effective and safe dental treatment. The dental care provided to a child with SJS type $1 \mathrm{~A}$ is reported.

\section{DESCRIPTION OF CASE}

A 9-year-old female patient diagnosed with SJS was brought to the Paediatric Dentistry Clinic of the Araraquara School of Dentistry, UNESP, Brazil with main complain of difficulty on oral hygiene and mastication due to tooth crowding. The child was born to healthy consanguineous parents (siblings on the mother's side) after fullterm pregnancy. The family history was positive for SJS and other neurological disorders. The child had other 6 siblings from the same parents: two dead at birth (twins), two diagnosed with SJS type 1B (4 and 8 years old) and two older children with neurological disorders.
The child is currently under treatment with a multidisciplinary team including speechlanguage therapist, physical therapist, neurologist and ophthalmologist. She is also under daily use of carbamazepine $(220 \mathrm{mg})$. There was no history of allergy to any medications.

The physical examination revealed mandibular retrognathism, maxillary prognathism, pursed lips (Figure 1), nasal voice, articular contractures and limitation of movement (Figure 2). The intraoral examination revealed narrow, higharched palate, moderate generalized gingivitis, tooth crowding and presence of a supernumerary tooth in the region of the maxillary right lateral incisor (Figure 3). The parents of the patient gave their signed informed consent for the publication of the pictures.

Some characteristics of SJS, like displacement and/or crowding of teeth and malocclusion may promote biofilm accumulation and increase the risk of caries, therefore, the treatment included preventive measures such as instructions on caries disease, diet counselling to reduce sucrose intake, training on toothbrushing and flossing to improve oral self-care skills, professional pumice prophylaxis and topical applications of $1.23 \%$ acidulated phosphate-fluoride gel (DFL, Jacarepaguá, RJ, Brazil). Sites on the occlusal surfaces of the permanent first molars considered at risk for caries development were sealed with a resinbased sealant (Fluroshield; Dentsply Ind. e Com. Ltda., Petrópolis, RJ, Brazil). Despite the patient demonstrate some level of collaboration, sessions were always short to avoid tiredness and lack of cooperation.

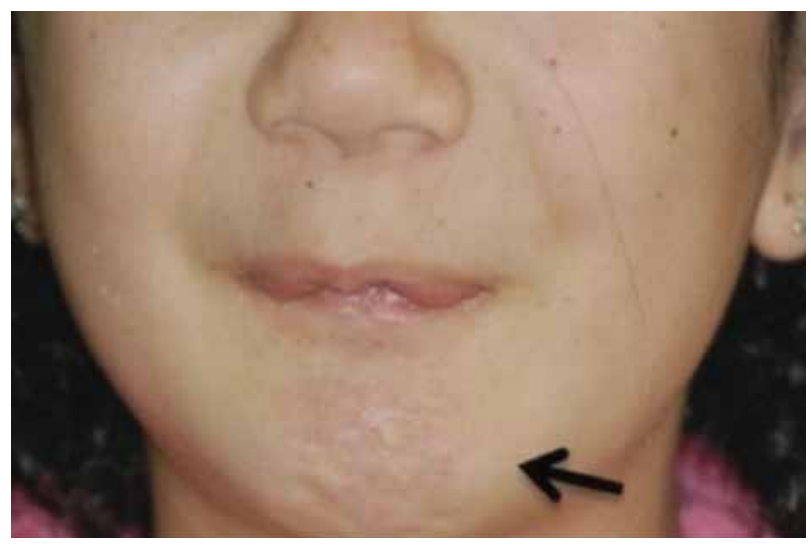

Figure 1 - Constant contraction of the lips characterizing myotonia of the facial muscles. 


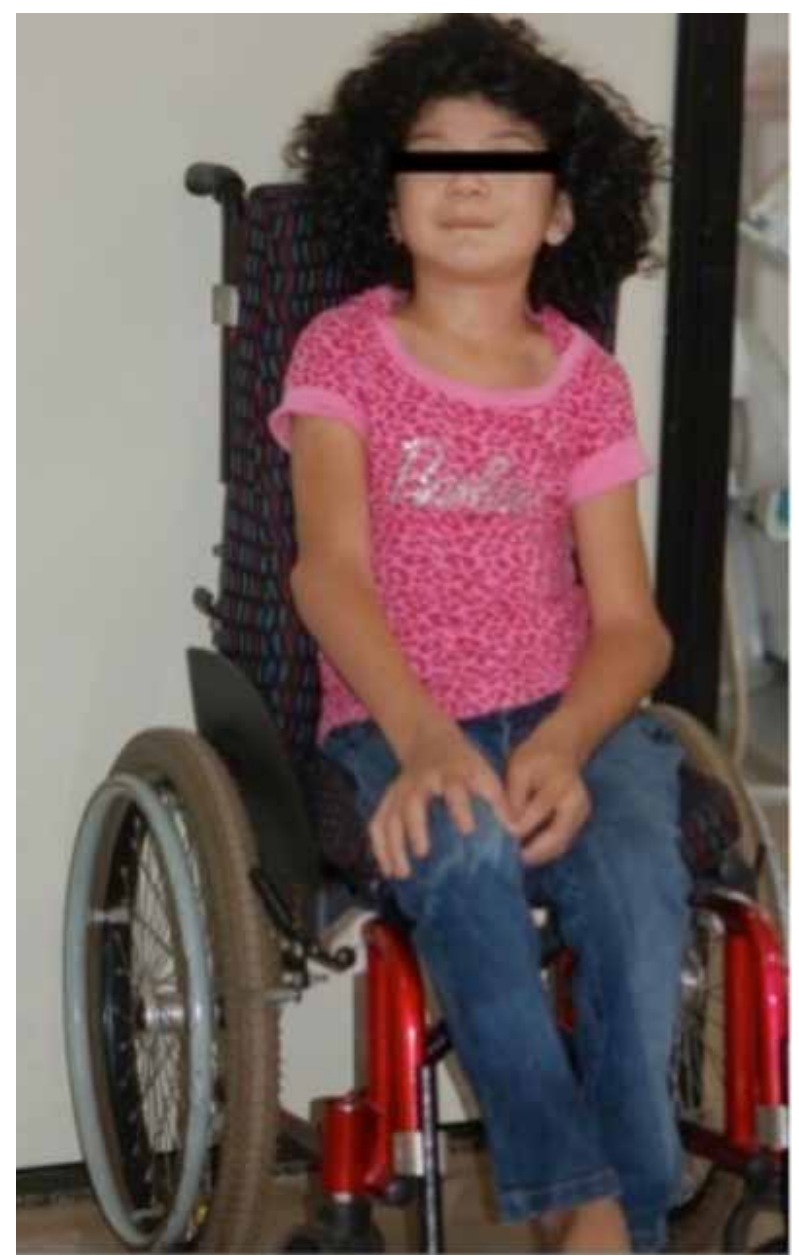

Figure 2 - Clinical manifestations of Schwartz-Jampel syndrome including hypertelorism, low-set ears, articular contraction and movement limitation.

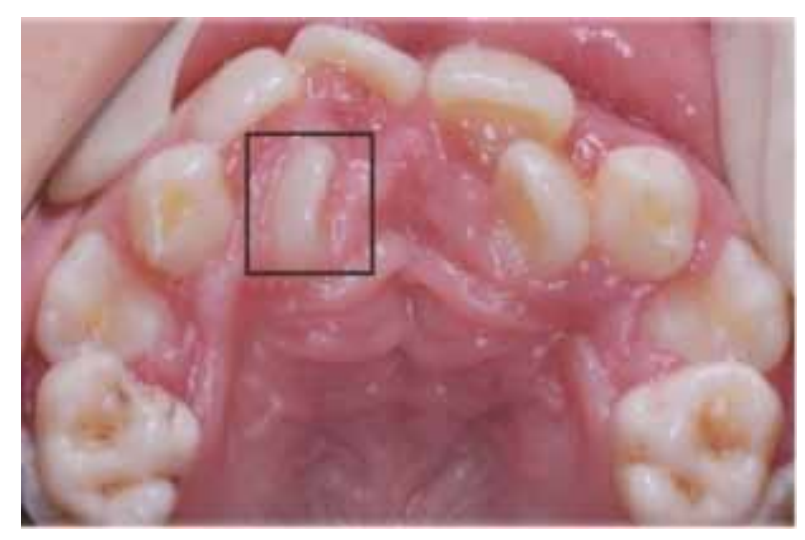

Figure 3 - Intraoral view showing tooth crowding in the maxillary arch, narrow, high-arched palate and a supernumerary tooth close to the maxillary right lateral incisor.

Extraction of the supernumerary tooth and the maxillary primary second molars, which had the distal root resorbed due to mesial (ectopic) eruption of the permanent first molars, was planned. Complete blood count, including clotting profile, was required before the surgical interventions in order to prevent possible intercurrences during the treatment. All results were normal. Paracetamol $(200 \mathrm{mg} / \mathrm{mL}$ ) was used as a postoperative analgesic. As the patient was always calm and collaborative, all procedures were undertaken in an outpatient setting (paediatric dentistry clinic) under local anaesthesia with no need of physical restraints, sedation or general anaesthesia. The child and her caregiver received instructions on how to proceed to avoid postoperative complications. The postoperative period was uneventful.

After completion of the preventive, restorative and surgical procedures, the patient was referred to orthodontic treatment for correction of tooth crowding. Orthodontic planning was done considering the limitations imposed by the strong perioral musculature contractions. Therefore, extraction of the four premolars was indicated to create space for further alignment of the teeth in the available intraoral space with a fixed appliance. The patient is currently in the beginning of the orthodontic treatment. Case progression is under continuing evaluation and satisfactory outcomes have been maintained with respect to oral health.

\section{DISCUSSION}

There are few reports in the literature describing SJS, which is characterized by very specific clinical maxillofacial features. Some of these aspects were present in this case scenario, namely micrognathia, narrow palate, hypertelorism and myopia. In addition, the existence of a supernumerary tooth, reported in this case, it seems to be an important finding in SJS, because this feature has not been reported in the literature yet. Thus, more case reports are required for clinical evidence of supernumerary as a SJS characteristic. When early diagnosis is established, the patient's quality of life can be substantially improved and the family can receive adequate genetic counselling. According to Al-Gazalli et al. [7], the occurrence of SJS is intimately related with parental consanguinity.

There is no current established treatment for SJS, and the available therapies are aimed only at attenuating the symptoms and preventing potential complications. Carbamazepine is usually the medication of choice in an attempt to reduce the continuous muscle fibre activity in patients 
with SJS. Additionally, it is always important to consider a multiprofessional treatment of these patients involving the areas of Medicine, Dentistry, Speech-Language Pathology and Audiology, Physical Therapy and Occupational Therapy.

In the present case, tooth crowding due to palate constriction and strong perioral musculature contractions are additional difficulties to oral hygiene, increasing the risk of caries and periodontal disease and reinforcing the importance of periodic professional dental care. The presence of facial myotonia may be challenging to orthodontic treatment in patients with SJS as it may lead to relapse of tooth crowding after alignment of teeth.

The importance of dental professionals in the management of patients with this disorder relates to the potential presence of multiple impacted teeth, tooth crowding, retrognathia, prognathism, open bite and other malocclusions, which affect severely the masticatory function and aesthetics. Dentists dealing with patients with SJS should also be aware of Von Willebrand's disease, which is a hereditary coagulation abnormality that can be associated with SJS [8], and request coagulation tests before any surgical procedure. In the present case, the results of the clotting profile were within normal ranges which ensured conducting surgical procedures with safety.

If general anaesthesia is indicated, the risk of malignant hyperthermia, the possible need of tracheotomy and the difficulty in endotracheal intubation due to limited temporomandibular movement, short neck and small larynx should always be considered. Careful administration of medications is also recommended as allergic reactions to certain medications are a frequent occurrence in affected individuals [5]. As our patient was cooperative, all procedures were performed under local anaesthesia, without any intercurrence. Paracetamol was prescribed postoperatively for pain control because the patient had no history of allergy to this medication.
Due to the diverse orofacial features of SJS, paediatric dentists may be one of the first health professionals to get in contact with children. Therefore, it is important that they are capable of recognizing the clinical manifestations of SSJ in order to refer for genetic confirmation possible carrier children that come across their dental offices. Likewise, when dealing with children with confirmed diagnosis of SSJ, paediatric dentists should be understand the need of planning the dental treatment considering the characteristics and possible complications associated with the syndrome in order to reduce the risks to patients, especially when surgical procedures are necessary.

\section{REFERENCES}

1. Schwartz 0, Jampel RS. Congenital blepharophimosis associated with a unique generalized myopathy. Arch Ophthalmol. $1962 \mathrm{Jul}$; 68:82-7.

2. Carod-Artal FJ, Fernandes da Silva TV, Christino-Marinho PB, Bonfim-Souza D. Schwartz-Jampel syndrome: a description of two adult siblings. Rev Neurol. 2002 Jul; 35(2):131-4.

3. Nessler M, Puchala J, Kwiatkowski S, Kobylarz K, Mojsa I, ChrapustaKlimeczek A. Multidisciplinary approach to the treatment of a patient with chondrodystrophic myotonia (Schwartz-Jampel vel Aberfeld syndrome): case report and literature review. Ann Plast Surg. 2011; Sep; 67(3):315-9.

4. Stephen LX, Beighton PH. Oro-dental manifestations of the SchwartzJampel syndrome. J Clin Pediatr Dent. 2002 Fall; 27(1):67-70.

5. Díaz-Serrano KV, Brandão CB, Brandão RB, Watanabe PC, Regalo SC. Dental findings and muscular-skeletal features in SchwartzJampel syndrome: case report of two affected siblings. Spec Care Dentist 2006; Sep-0ct; 26(5):225-9.

6. Dhanrajani PJ and Abdulwassie HM. Schwartz-Jampel syndrome: a case report. Indian J Dent Res. 1996; Jul-Sep; 7(3):107-9.

7. Al-Gazali LI, Varghese M, Varady E, Al Talabani J, Scorer J, Bakalinova D. Neonatal Schwartz-Jampel syndrome: a common autosomal recessive syndrome in the United Arab Emirates. J Med Genet. 1996; Mar; 33(3):203-11.

8. Kuriyama M, Shinmyozu K, Osame M, Kawahira M, Igata A. Schwartz-Jampel syndrome associated with von Willebrand's disease. J Neurol. 1985; 232(1):49-51.

Profa. Dra. Elisa Maria Aparecida Giro (Corresponding author)

Faculdade de Odontologia de Araraquara, Departamento de Clínica Infantil

Rua Humaitá, 1680. Centro, Caixa Postal: 331

Cep: 14801903 Araraquara, SP, Brasil

Phone: + 55 (16) 3301-6336. Fax: + 55 (16) 33016329.

Received: 2013 Feb 14

E-mail: egiro@foar.unesp.br 